\title{
LA CONTRAOFENSIVA CONSERVADORA EN AMÉRICA LATINA
}

\author{
Carlos FIGUEROA IBARRA ${ }^{1}$ \\ Octavio H. MORENO ${ }^{2}$
}

\begin{abstract}
Resumen
En este trabajo se presenta una visión crítica acerca del debate que durante los últimos años ha despertado la llegada de gobiernos de izquierda en América Latina, en específico respecto a aquellos grupos que se han manifestado abiertamente como contrarios a los cambios de gobiernos en los países de la zona. Se plantea una revisión de las transformaciones que la política en A. L. y el mundo ha sufrido a raíz de la crisis del neoliberalismo y la caída de los antiguos paradigmas sobre el desarrollo político y económico. Este escenario de cambios se aborda bajo la categoría de "posneoliberalismo", referido como un proceso de cambio en los paradigmas dominantes que se han visto modificados hasta el punto de arrojar más preguntas que respuestas. A raíz de estos cambios, se analiza la forma como el pensamiento que denominamos "conservador" ha abordado el surgimiento de gobiernos de izquierda en países como Venezuela, Ecuador y Bolivia, hasta manifestarse abiertamente como "reaccionario" al cambio político mediante el uso de sus recursos políticos y económicos. Finalmente se presenta un análisis sobre categorías como "populismo" o "demagogia", conceptos que han cobrado fuerza en el debate político contemporáneo, así como también la presencia de inquietudes acerca del carácter antidemocrático de los gobiernos de izquierda en América Latina. Al respecto, la formulación más reciente asume el escenario en términos de un conflicto entre "democracia" y "autoritarismo", como sucedía en tiempos de la guerra fría.

Palabras Clave: crisis, posneoliberalismo, conservadurismo, democracia, populismo.
\end{abstract}

\footnotetext{
Abstract

This piece of work presents a critical vision on the debate started last years by the arrival of left side governments in Latin America, specificly on those groups openly declared as opposite to the change of government in the countries of the zone. It is presented a review of the transformations that the politics in Latin America and the world has suffered immediately after

${ }^{1}$ Profesor-investigador del posgrado en sociología del Instituto de Ciencias sociales y Humanidades (ICSYH) "Alfonso Vélez Pliego" de la Benemérita Universidad Autónoma de Puebla (BUAP) (carlosfigueroaibarra@yahoo.com.mx)

${ }^{2}$ Doctorante del posgrado en Sociología del ICSYH- BUAP (octaviohmoreno@hotmail.com)

Fecha de recepción del artículo: Mayo 2010

Fecha de evaluación: Junio 2010
} 
the crisis of the neoliberalism and the fall of the former paradigms on the political and economic development. This scenario of changes is approached under the category of "postneoliberalism", refered as a process of change in the dominant paradigms that have met transformed up to the point of throwing more questions that answers. The form is analyzed as the thought that we name "conservative" has approached the emergence of governments of left side in countries as Venezuela, Ecuador and Bolivia, to manifest itself openly as a "reactionary" to political change through the use of political and economic resources. Finally, an analysis on categories like "populism" or "demagoguery" is presented, concepts that have gathered strength in the political contemporary debate, as well as the presence of worries over the undemocratic character of the governments of left side in Latin America. In the matter, the most recent formulation assumes the scenario in terms of a conflict between "democracy" and "authoritarianism" as well as it was happening in times of the cold war.

Key words: crisis, post-neoliberalism, conservatism, democracy, populism.

\section{Résumé}

Ce document présente une vision critique sur le débat ces dernières années a suscité l'arrivée de gouvernements de gauche en Amérique latine, en particulier en ce qui concerne les groupes qui se sont exprimés ouvertement contre tout changement de gouvernements dans les pays de la région. Nous proposons une révision des changements de politique en $\mathrm{A}$. L. et le monde a souffert apropose de la crise du néolibéralisme et de l'effondrement du vieux paradigmes du développement politique et économique. Ce scénario de changement est abordée dans la catégorie des "post-néolibéralisme", considéré comme un processus de changement dans les paradigmes dominants qui ont été transformés au point de jeter plus de questions que de réponses. Il analyse comment la pensée que nous appelons «conservateur» a abordé l'émergence de gouvernements de gauche dans des pays comme le Venezuela, l'Équateur et la Bolivie, jusqu'à ce manifester ouvertement comme «réactionnaire» du changement politique par l'utilisation de leurs ressources politiques et économiques. Enfin, nous présentons une analyse des catégories telles que le «populisme» et de «démagogie», concepts qui ont été faites dans le débat politique contemporain, ainsi que la présence de préoccupations au sujet de la nature non démocratique des gouvernements de gauche en Amérique Latine. À cet égard, la formulation la plus récente du conflit suppose en termes de conflit entre la «démocratie» et «autoritarisme» comme cela s'est produit dans les jours de la guerre froide.

Mots-clé: crise, post-néolibéralisme, conservatism, démocratie, populisme.

En los últimos veinte años hemos tenido el raro privilegio de vivir acontecimientos memorables. El mundo ha asistido a cambios vertiginosos que han estremecido a los grandes paradigmas de la modernidad y han hecho envejecer teorías. Las certezas de hace treinta años se han convertido en incertidumbres y lo que no parecía poder suceder ha sucedido ante el estupor de los que no lo creían posible. Esto es particularmente cierto para la izquierda y esa traslación de certezas a incertidumbres la ha puesto en una notable crisis ideológica. Recordemos solamente el optimismo reaccionario expresado por Francis Fukuyama en su memorable conferencia impartida en la Universidad de Chicago en el verano de 1989. La humanidad asistía al fin de la historia y dos paradigmas señalaban dicho fin: el liberalismo y la economía de mercado (Fukuyama, 1989; 1992). En otras palabras el devenir histórico había llegado a dos puertos de arribo más allá de los cuales no había alternativa: la democracia schumpeteriana y el neoliberalismo. El inicio de la década de los noventa no podría haber sido más aciago para la izquierda mundial: el socialismo real, 
referencia crítica o acrítica de dicha izquierda, se había venido abajo como castillo de naipes; el estado de bienestar y el paradigma keynesiano se encontraban en crisis profunda como lo evidenciaba la crisis fiscal y la inflación combinada con el estancamiento económico; el sujeto colectivo que durante décadas había sido visto como el sepulturero del capitalismo, el proletariado, empezaba a ser disuelto merced a la nueva etapa de acumulación capitalista, la acumulación flexible más conocida como neoliberal.

En efecto, parecía ser cierta la afirmación de Margaret Tatcher en el sentido de que no había alternativa y también parecía ser cierta la afirmación de Ronald Reagan de que el Estado era el problema no la solución. La fetichización del mercado, nuevo dios de la prosperidad, fue llevada a sus máximas consecuencias. No faltó el ideólogo neoliberal que aseveró en algún momento que el mundo sería mejor cuando el Estado fuera hecho una bolita de papel y arrojada a la taza del inodoro. Lo que se interponía entre la felicidad humana y el mercado que la podría obtener, era el asfixiante Estado que maniataba al primero e impedía que se desarrollara la productividad. Cuando el mercado fuera dejado a su libre albedrío la productividad crecería inconteniblemente y la riqueza se derramaría sobre toda la sociedad. Asistiríamos entonces a una fase de prosperidad y felicidad humana. De acuerdo con Fukuyama, sería el fin del devenir histórico. He aquí pues, el ABC del triunfalismo reaccionario que vivimos durante aproximadamente dos décadas.

Sin embargo, al estupor que la izquierda ha vivido desde hace más de dos décadas se une ahora la perplejidad de la derecha. Resulta asombroso lo efímero que resultó ser el tiempo histórico que se postulaba como el definitivo en la historia de la humanidad. El fin de la historia tuvo la duración de un respiro en materia de tiempos históricos. Si el socialismo real tardó aproximadamente 60 años para empezar a mostrar su inviabilidad, el paradigma triunfante de la derecha, el neoliberalismo, ha tenido una duración todavía menor. Hoy podemos decir que no solamente la izquierda tiene las manos llenas de incertidumbres, sino también la derecha. En esto parecen coincidir analistas de la propia derecha, del centro y de la izquierda. La crisis mundial que estalló en septiembre de 2009, ha tenido la virtud de arrojarle una cubeta de agua helada al triunfalismo reaccionario. Ese triunfalismo reaccionario que desde el punto de vista académico parecía tan simplista, pero que en los ámbitos de los poderes mundiales, llegó a tener la fuerza que siempre tienen los prejuicios bien arraigados. Así las cosas, en el contexto de la crisis, Nicolás Sarkozy a quien no puede conceptuársele como de izquierda, nos hace saber una crítica franca a uno de los rasgos del neoliberalismo: la hipertrofia del capital financiero, especulativo y hasta ficticio. Dice Sarkozy: "El día que dejemos de construir trenes, aviones, automóviles y barcos, ¿Qué quedará de la economía francesa?" y se responde él mismo: "Recuerdos. Yo no quiero hacer de Francia una mera reserva turística". Y concluye Sarkozy con una frase lapidaria: "El capitalismo de laissez-faire ha muerto" (Bello, 2009). Desde una perspectiva keynesiana, el premio Nobel de Economía, Joseph Stiglitz, declaró desde los albores de la crisis mundial que se vivía el final del fundamentalismo de mercado y que "en ese sentido, la crisis de Wall Street es para el fundamentalismo de mercado lo que la caída del muro de Berlín fue para el comunismo." (Stiglitz, 2008a). En la perspectiva de la socialdemocracia neoliberal y abanderada de la tercera vía, el primer ministro británico Gordon Brown anunció después de la reunión del G20 en marzo de 2009, que el Consenso de Washington había muerto. Brown no hacía sino repetir lo que en realidad ya había expresado el Banco Mundial en su informa anual de 2007 (Esteva, 2009). Desde la óptica de la misma cúspide del capital financiero, George Soros concluyó que el paradigma del fundamentalismo de mercado con su postulado de que los mercados podrían corregirse a sí mismos, había demostrado ser falso. Ello implicaba, según Soros, que la crisis mundial nos hacía lidiar no solamente con el colapso del sistema financiero, sino con el colapso de una concepción del mundo (Esteva, 2009). Finalmente, desde el horizonte de la izquierda, Ignacio Ramonet afirmó que el terremoto que estamos viviendo había precipitado el fin de "una era del capitalismo", aquella que Ronald Reagan sintetizó con la 
famosa frase que ya hemos mencionado: "El Estado no es la solución, es el problema". Viviremos ahora, afirmó Ramonet, el regreso del Estado (Ramonet, 2008).

El pasmo conservador se refuerza con la amplitud de la crisis que estamos viviendo. No basta con la inercia del triunfalismo de las décadas pasadas que afirma que lo que estamos viviendo es una crisis hipotecaria, o una crisis financiera o una crisis bancaria, en suma un incidente menor en la marcha de los mercados (Borón, 2009). La esperanza en que el capitalismo goza de buena salud contrasta con los datos que hemos empezado a conocer. Las cifras oficiales en los Estados Unidos de América revelan una crisis severa. Al comparar el último trimestre de 2007 con el mismo período de 2008, la contracción del PIB que se estimaba sería de 3.8\% resultó ser casi el doble: $6.2 \%$. En el Japón las cifras parecen ser más severas, pues el PIB cayó en un $12 \%$ en el mismo período. En Europa la situación puede ser igual o peor después del derrumbe financiero de Islandia y la amenaza de bancarrota en varios países de Europa del este como Polonia, Hungría, Ucrania, Letonia y Lituania entre otros, situación que podría arrastrar a las bancas acreedoras en Suiza y Austria (Beinstein, 2009).

Independientemente de que estas previsiones se hicieran realidad, lo que hay que constatar es la integralidad de la crisis. En efecto, la hipótesis es que vivimos hoy una crisis mucho más compleja e integral que la que se vivió en 1929. Sería una crisis inédita y multifacética, una crisis de lo que Braudel llamaba civilización occidental (Guillén, 2009). Vivimos pues una crisis que afecta las bases mismas de la estabilidad social y pone a prueba la supervivencia del sistema (Esteva, 2009). Una crisis civilizatoria cuya duración, profundidad y alcances geográficos serán mayores que los que observaron las crisis precedentes (Borón, 2009). Que esto lo diga un académico de izquierda puede originar alguna duda, pero una similar opinión la encontramos en Paul Volcker, un personero del establecimiento financiero quien ha afirmado que esta crisis es muy superior a la de 1929 (Beinstein, 2009). Lo que probablemente sustente todas estas afirmaciones, es que vivimos hoy una crisis que es integral porque expresa una articulación de diversas crisis: la crisis financiera, la crisis ambiental, la crisis alimentaria y la crisis energética (Borón, 2009). Y sucede que una crisis retroalimenta a la otra como sucede con las crisis energética y alimentaria, en tanto que el costo de los alimentos depende en buena medida del costo de los hidrocarburos por el papel de la petroquímica en la producción de cereales. La situación se agrava más porque las regiones cerealeras de Estados Unidos, Argentina, Australia, China, Oriente Medio y África están sufriendo una notable sequía (Klare, 2009) y porque extensiones de tierra que podrían servir para la producción de alimentos se están reconvirtiendo en tierras de producción de agrocombustibles (Borón, 2009). La crisis financiera agrava la crisis alimentaria: antes del estallido de la depresión ya existían 850 millones de hambrientos en el planeta, hoy en el contexto de dicha depresión, 100 millones más de personas con hambre se han agregado a la cifra original (Vivas, 2008).

Si nos hemos permitido hacer este excursus por la crisis mundial, es porque esta misma ha dejado maltrecho al triunfalismo reaccionario. Hoy se empieza a plantear la posibilidad de que estemos viviendo en el umbral del posneoliberalismo. Ciertamente el que esto se haga realidad no depende de la evolución de la economía, sino de los avatares de la política. Solamente si existen fuerzas políticas y sociales que impongan una nueva época que deje atrás el fundamentalismo de mercado, será posible vivirla. Mientras eso no suceda podremos seguir diciendo que el triunfalismo neoliberal ha resultado ser uno de los grandes logros hegemónicos del paradigma reaccionario. No en balde se ha dicho que este paradigma ha tenido mayor éxito en la ideología que en la economía. Resulta asombroso la persistencia hegemónica del neoliberalismo cuando se observa el fracaso de las fugas hacia adelante que el capitalismo ha ensayado : la nueva fase de acumulación neoliberal, la globalización que integró como nunca antes a vastas zonas de la periferia capitalista y aprovechó mercados de materias primas y fuerza de trabajo baratos y finalmente la traslación hacia el capitalismo de hipertrofia financiera con el efecto nefasto de una bifurcación entre una economía financiera hiperactiva y 
una economía real estancada (Bello, 2009). El optimismo conservador no se condice con lo que ha venido sucediendo en el capitalismo mundial aun antes del arribo del neoliberalismo. Las cifras promedio de crecimiento global indican una creciente desaceleración de la economía mundial que viene desde hace aproximadamente medio siglo: en los años sesenta el promedio de crecimiento global fue de $3.5 \%$, en los setenta fue de $2.4 \%$, en los ochenta de $1.4 \%$ y en los noventa de $1.1 \%$ (Bello, 2009). El ataque neoliberal al estado de bienestar de ser el gran responsable de la estanflación, resultó infundado pues las anteriores cifras demuestran que el neoliberalismo fue inferior al período precedente en lo que se refiere al ritmo de crecimiento.

\section{La derecha y sus límites en América Latina. ¿En el umbral del posneoliberalismo?}

Ciertamente la crisis mundial no necesariamente implica el declive de la derecha a nivel mundial. Es bastante conocido cómo la crisis de 1929 no dio paso a una revolución mundial o a revoluciones en países determinados. Más bien creó condiciones para que en Alemania e Italia el fascismo y el nazismo se desplegaran y el mundo se viera envuelto en una gran conflagración. En la crisis actual, por fortuna no se ven indicios fuertes de que partidos de extrema derecha puedan convocar a grandes sectores y generar situaciones parecidas al del período de entreguerras. No obstante, a diferencia de lo que sucede en América latina, la derecha se encuentra en una situación cómoda en Europa. El neoliberalismo generó una ventana de oportunidad para que los partidos y grupos políticos de derecha se fortalecieran al lograr un arraigo entre los grupos menos favorecidos por la gran concentración de capitales: lumpenproletarios, pequeños empresarios y desempleados. Partidos y grupos que tomaron como banderas la lucha en contra de la inmigración y contra la pertenencia de sus países a la Unión Europea. La ultraderecha igualmente se hizo presente asumiendo postulados de tipo racistas, xenófobos, fundamentalistas religiosos e intolerantes hacia el multiculturalismo (Rodríguez, 2003). Ciertamente la derecha el recién pasado 4 de octubre perdió las elecciones en Grecia y lo mismo sucedió poco antes en Portugal. Sin embargo, en España los socialistas y en Gran Bretaña los laboristas se encuentran a la defensiva, mientras que en los otros países como Francia, Alemania e Italia, los liderazgos de la derecha se encuentran consolidados. Y en los países de Europa del Este la izquierda es particularmente débil (Meyer, 2009). Los liderazgos de Sarkozy, de Angela Merkel se observan consolidados. Inclusive el de Silvio Berlusconi, pese a sus escándalos sexuales. Ciertamente, la crisis mundial no ha implicado el repunte de la izquierda en los países centrales, pese a que en los Estados Unidos provocó el desplazamiento de la derecha inserta en el Partido Republicano y la llegada al gobierno de una fuerza ubicada en el centro (Meyer, 2009).

El panorama resulta enteramente diferente en América latina. Aún antes de septiembre de 2009, al observar el panorama político en la región, era posible constatar los síntomas de la crisis del neoliberalismo. En efecto, se podían contar aproximadamente 16 o 17 presidentes de la región derrocados porque quisieron llevar el neoliberalismo hasta sus últimas consecuencias. Tales síntomas comprendían también la emergencia de movimientos sociales más o menos poderosos luchando contra las consecuencias sociales de dicho paradigma económico. A partir de la sublevación de Caracas en 1989, se han venido observando los conflictos sociales que no son sino el síntoma de que las promesas neoliberales han resultado un fiasco. Al caracazo pueden agregarse la sublevación zapatista de 1994, el largo proceso de rebeliones y protestas populares iniciadas en Santiago del Estero en la Argentina de 1996 las cuales culminaron con la sublevación de diciembre de 2001, el ciclo de protestas populares observadas en Bolivia y Ecuador entre 2000 y 2005, el ascenso del liderazgo de Andrés Manuel López Obrador en México entre 2003 y 2006. Observamos pues, una suerte de crisis hegemónica del neoliberalismo en América latina, aun cuando la extensión y profundidad de dicha crisis tiene que ser matizada en el amplio arco que comprende a países como Chile en donde la hegemonía neoliberal es plena hasta países como 
Venezuela, Bolivia y Ecuador donde por el contrario la crisis hegemónica es profunda. Los movimientos sociales que ha generado el agotamiento neoliberal, han efectuado una traslación hacia movimientos políticos y electorales y han dado origen en mayor o menor medida a gobiernos de izquierda o centro izquierda que de manera frontal o moderada han cuestionado al fundamentalismo de mercado. Al triunfo de Hugo Chávez en la Venezuela de 1999, le han sucedido el de Lula que ganó la presidencia de Brasil en 2002, Kirchner que lo hizo en Argentina en 2003, Tabaré Vázquez quien triunfó en 2004, Evo Morales en 2005, Rafael Correa en Ecuador y Daniel Ortega en Nicaragua en 2006, Cristina Fernández nuevamente en Argentina durante 2007, Lugo en el Paraguay en 2008 y finalmente Mauricio Funes en El Salvador en este año de 2009. La influencia de estos hechos ha sido tan grande que incluso un gobierno como el de Zelaya en Honduras inició un viraje hacia la izquierda, con las consecuencias de todos conocida.

Todos estos hechos, articulados al contexto de la crisis mundial, nos hacen conjeturar que acaso estábamos viviendo los estertores del neoliberalismo, que tal vez estemos viviendo el umbral del posneoliberalismo (Figueroa, 2009). En América latina esto es particularmente evidente. El desarrollo de la protesta popular, el surgimiento de movimientos sociales que se convierten en electorales, y eventualmente cristalizan en gobiernos de izquierda, tienen un sustento material. Éste está constituido por los magros resultados neoliberales que se ven confirmados cuando se examinan los promedios de crecimiento del PIB en los países latinoamericanos entre 1997 y 2005. Venezuela, Paraguay y los países del Caribe con menos del 2\%, a lo sumo el 2\%. Uruguay, Brasil, Colombia, Ecuador, México y Argentina con menos del 3\%. Guatemala, El Salvador, Honduras y Nicaragua lograron sobrepasar el 3\%, mientras que Costa Rica y República Dominicana sobrepasaron el 4\%. El país que se ha convertido en el paradigma latinoamericano del neoliberalismo, Chile, llegó a sobrepasar el 5.5\% de promedio de crecimiento del PIB en esos 9 años (Long: 2008: 162). Cifra que parece impresionante si se le compara con el resto de los países de América latina y del Caribe, pero que empalidece si se le contrasta con el $6 \%$ de crecimiento promedio del PIB que tuvo México durante el período del desarrollismo (Babb, 2001). A fines del siglo XX y principios del siglo XXI, México presentaba una tasa promedio de crecimiento de $2 \%$, cifra que evidenciaba la mediocridad económica que caracterizó a los gigantes económicos de la región (México, Argentina y Brasil).

\section{Las armas de la derecha convertidas en reacción conservadora.}

Como buena parte de los sujetos políticos, la derecha en América latina es una realidad heterogénea. Se encuentra encabezada por las cúspides empresariales, por las cúpulas de los partidos de derecha, por los dueños de los grandes medios de comunicación, por la alta jerarquía de la iglesia católica. En términos generales su fuerza ha radicado en el ejercicio del poder del Estado, aún cuando en la actualidad el control de los medios de comunicación electrónicos e impresos resulta verdaderamente decisivo. En México, ello resulta particularmente evidente como lo demuestra el papel en la difusión del pensamiento único por parte del duopolio televisivo (Televisa-TVAzteca). En Guatemala, la situación puede ser matizada en lo que se refiere a la televisión, no así en lo que se refiere a la radio, pero basta examinar en los medios impresos las proporciones de editorialistas neoliberales y los que tienen una postura crítica para constatar la función ideológica que cumplen dichos medios. Es a través de estos medios que se ha intentado construir una hegemonía social caracterizada por su recuperación del individualismo, el privatismo y los valores tradicionales, respaldados bajo la figura de gobiernos autoritarios, en los cuales resulta fundamental la búsqueda de la inmovilización social para contrarrestar la contestación (Miranda, 2007).

El uso de los medios de comunicación ha servido a la derecha como una eficaz herramienta para conservar su poder de penetración ideológica en las poblaciones nacionales, siendo en buena medida este el medio que les ha permitido, a pesar de las derrotas, mantenerse presente como fuerza política. El uso estratégico de estos medios ha permitido generar una tendencia de opinión 
dirigida a culpar al "sistema institucional" como causa de: la fragilidad en el empleo, la degradación de los servicios y la seguridad social. La respuesta que ofrecen los grupos de derecha a estos problemas, originalmente provocados por las políticas neoliberales, es el uso de la "mano dura", en el entendido que sólo mediante la represión estatal se puede combatir contra las malas costumbres y los vicios sociales (Castro, 2010). Esta tendencia se refleja en la construcción de poderes ejecutivos fuertes que someten a los otros órganos del estado, imponiendo una concentración del poder en lo que se refiere a la gestión pública, una tendencia claramente visible en el caso de Colombia. El objetivo final en esta contraofensiva es liberar a la economía capitalista neoliberal de las restricciones que el humanismo, la tradición liberal y las conquistas de los movimientos populares lograron durante los últimos años.

Como muestra de lo anterior, en los países en los cuales la fuerzas de izquierda tienen un perfil decididamente antineoliberal y han conquistado el gobierno, nos referimos específicamente a los casos de Venezuela, Bolivia y Ecuador, la reacción conservadora ha hecho uso de los medios de comunicación hasta para romper la institucionalidad. Tal es el caso de Venezuela con motivo del golpe de estado que derrocó durante 48 horas al presidente Hugo Chávez. El papel de los medios de comunicación resulta decisivo porque es a través de ellos que se ha construido la hegemonía conservadora sobre amplios sectores de la población. Basta recordar la campaña de linchamiento mediático que sufrió en México López Obrador en los meses previos a las elecciones de julio de 2006 y cómo esta campaña logró abatir las preferencias electorales de las cuales gozaba, para ilustrar la importancia de los medios de comunicación en la construcción de dicha hegemonía conservadora.

Además de los medios de comunicación, juegan un papel decisivo en buena parte de los países de América latina el conservadurismo católico. El conservadurismo católico es una herencia colonial de gran importancia en América latina. En Guatemala y en otros países tal conservadurismo se mezcló con el anticomunismo que generó la guerra fría y estos dos elementos articulados fueron suficientes como para concitar el apoyo a la derecha extrema por parte de grandes sectores de la población. Tomando en cuenta la aseveración de que en la Iglesia Católica coexisten diversas orientaciones, el hecho cierto es que el púlpito ha servido de manera decisiva en la conformación de un apoyo político a la derecha. Este es el momento de hacer una distinción ideológica en el campo de la derecha. En ella coexisten al menos dos vertientes, la derecha neoliberal que se ha convertido en predominante montada en los vientos de la globalización y el agotamiento del keynesianismo y por otra parte, una derecha tradicional, de viejo cuño, a la cual podríamos calificar de derecha clerical. En México, esta derecha se asentó en el Partido Acción Nacional (PAN) como reacción al nacionalismo revolucionario que durante décadas se instaló en el Partido Revolucionario Institucional (PRI). Hoy esta diferenciación se hace más compleja porque el PRI abandonó el nacionalismo revolucionario y hoy es expresión de la derecha neoliberal, pero también el PAN ha abrazado dicho ideario. Aun así es posible distinguir en el PAN a esa derecha clerical, la cual incluso se aglutina de manera secreta en organizaciones como el Yunque, las cuales están asociadas con las tendencias más conservadoras de la Iglesia Católica. En el gran partido de la derecha en El Salvador, también ha sido posible hacer la distinción ideológica entre las dos derechas referidas. Resulta interesante observar la evolución ideológica de ARENA del predominio de una vieja derecha anticomunista y clerical, encarnada en el liderazgo del mayor Roberto D'Aubuisson hacia una más pragmática derecha neoliberal que se empieza a observar a partir del liderazgo de Cristiani. Ciertamente las fronteras entre una y otra son difusas, pero existen. En Guatemala esta transición entre la vieja y la nueva derecha fue evidente con la extinción del otrora poderoso Movimiento de Liberación Nacional (MLN), expresión conspicua de esa derecha clerical y anticomunista. No en balde el lema del MLN, por todos los guatemaltecos hoy recordado, fue "Dios, Patria, Libertad". Hoy en Guatemala la derecha también se ha vuelto neoliberal y este cambio es visto como modernización. De manera esquemática podemos decir que esta modernización radica en que los partidos de la derecha ha cambiado su orden de prioridades: la 
defensa de Dios, la religión y las llamadas buenas costumbres, ha sido sustituida en gran medida por defensa de un nuevo dios, el mercado.

Resulta importante agregar a los componentes ideológicos de la derecha en América latina, el racismo. Este es particularmente evidente cuando la derecha se siente amenazada y empieza a actuar como reacción conservadora. Es evidente en que en toda la región que viene de una matriz colonial en las que las clases se diferenciaron por el color de la piel y los sectores subalternos se convirtieron en etnias, el racismo juega un papel fundamental. Hoy el color de la piel no tiene la importancia que tuvo en el pasado en la adscripción a las clases sociales, pero el atavismo colonial del racismo sigue siendo muy fuerte. En países con poblaciones indígenas mayoritarias o demográficamente importantes como Guatemala, Ecuador, Perú y Bolivia ser indígena todavía es estar en la escala más baja de la sociedad. En Guatemala es muy conocido el dicho de los ladinos de "seré pobre pero no indio". El no ser indio se convierte en una suerte de premio de consolación, en la constitución imaginaria de un "nosotros" que hace parte de una falsa comunidad al blanco oligarca de apellido de abolengo y al mestizo o indígena aculturado que vive en las áreas marginales de las ciudades. El racismo, latente en los más diversos sectores sociales, surge en toda su plenitud cuando los indígenas se empoderan, cuando, como sucede hoy en Bolivia, llegan al gobierno. Lo mismo acontece cuando una fuerza social subalterna se vuelve política y llega al gobierno como ha sucedido en Venezuela. También sucede cuando una fuerza política, aunque sea moderada, derrota a la derecha y llega al gobierno. O cuando una fuerza de estas características se convierte en una amenazante realidad electoral. El racismo se despliega en bromas acerca de la fealdad de los nuevos gobernantes o de las primeras damas, en el uso de los epítetos más ofensivos y de contenido clasista como el de naco usado para atacar a López Obrador en México, o el de zambo para ofender a Hugo Chávez en Venezuela. El problema de fondo en todo esto es que para la reacción conservadora resulta imperdonable que esa masa de pobres, de indios o negros se vea empoderada y se inserte en el Estado, territorio hasta hace poco monopolizado por las élites tradicionales. A este respecto, Evo Morales declaraba recientemente en Cochabamba que uno de los problemas en Bolivia era que los blancos -que siempre habían hecho política-, no le perdonaban a los indios que hicieran política. Resulta ofensivo para las oligarquías regionales de los departamentos de la media luna boliviana, que un indio los gobierne. Tal cual lo dijo Rubén Costas, el gobernador de Santa Cruz, en el momento mismo del triunfo de Evo Morales en el referéndum revocatorio de agosto de 2008: "como el señor Evo Morales será revocado en Santa Cruz, no vamos a decir que no venga nunca más, que venga pero de paseo porque aquí no va a gobernar" (CEDIB, 2008).

El problema de fondo cuando se analizan las distinciones entre la izquierda y la derecha, es la percepción que tienen con respecto a la participación de los sectores subalternos en el gobierno y en el Estado. Los sectores conservadores han sido constantes en la aversión a lo popular, a lo indígena, a lo negro, si trascienden de la mera estampa folklórica o del atractivo turístico. Esto resulta particularmente evidente en un país como Guatemala. Pero es una constante en otros países de la región: el indígena exaltado es el que ya no existe. El indígena actual encaja mejor en los cuentos de costumbres y en los relatos pintorescos. El indígena empoderado, el indígena en el gobierno causa pavor a la derecha y a los sectores sobre los que influye. Más aun, puede decirse que el indígena en el gobierno es tolerado si sirve para legitimar a un gobierno de no indígenas. Más allá de ese punto comienza la demofobia, la aversión a lo popular. La demofobia es una tradición política de larga trayectoria. Se puede constatar en el desprestigio de la democracia como forma de gobierno durante aproximadamente dos mil años. Basta ver la penosa lucha por el sufragio universal en el mundo entero para de nueva cuenta constatarlo. Finalmente puede observarse en el paradigma democrático que finalmente ha triunfado: el meramente procedimental. La democracia que se prefiere es aquella en la cual la participación popular se reduce al momento electoral. Las elecciones adecuadas son aquellas en las cuales el demos es convocado a elegir mediante el voto cual de las élites va a gobernar. La democracia elitista preferiblemente si es llevada a un simplemente elitismo es el escenario ideal para la derecha. En Guatemala puede verse 
un ejemplo claro en la reforma constitucional que durante 2009 ha propugnado un sector conservador.

La derecha puede transformarse en reacción conservadora por un amplio abanico de razones. A veces no se necesita un gobierno de izquierda y de contenido popular para que ello suceda. Basta con que ese gobierno quiera mantener una distancia y una autonomía relativa con respecto a los sectores tradicionales del poder fáctico. La desmesura en la reacción puede observarse no solamente en América latina sino aun en los Estados Unidos de América: hoy un sector importante del Partido Republicano está convencido de que el gobierno de Barack Obama tiene rasgos socialistas (Meyer, 2009). Obviamente una retórica socialista o popular fácilmente agita el fantasma del comunismo, pero también medidas nacionalistas, estatistas, redistributivas, antiimperialistas o cualquier otra política pública que pueda ser calificada de populista. Al respecto la visión conservadora sobre el viraje hacia la izquierda en algunos países de América Latina, refiere que la democracia procedimental supera las diferencias entre la izquierda y la derecha, y que actualmente sólo se puede abordar la problemática política bajo el binomio "democraciaautoritarismo" (un binomio que fue utilizado en los tiempos de la guerra fría para plantear el conflicto político entre socialismo y capitalismo). Superando la dicotomía de pobres contra ricos y estableciendo que las fuerzas que se aboquen a la transformación del estado en busca de la igualdad social ponen en riesgo el camino trazado por la modernidad política (Reyna, 2006). En este contexto se hace evidente que lo que más terror ocasiona en la reacción conservadora es que el poder político adquiera un contenido popular. Y en esto la derecha no se equivoca, como cierto es que a diferencia de la izquierda, la derecha rara vez se equivoca de enemigo. En los albores del siglo XXI, un gobierno se convierte en revolucionario no tanto por las expropiaciones y redistribuciones que hace, sino por el grado en que en su seno se observa la participación popular. Participación popular en el sentido de poder constituyente, de integración de los de abajo en la toma de decisiones en los rumbos fundamentales del Estado. Cuando esto sucede, al igual que en algún momento visualizó al Estado, para la reacción conservadora la democracia liberal representativa se convierte en un asfixiante dogal. Hay múltiples ejemplos de ello en la historia de América latina. Para citar los que fácilmente se evocan: Guatemala en 1954, Chile en 1973, Venezuela en 2002, Bolivia en 2008, Honduras en 2009.

Durante los años de la guerra fría la propaganda anticomunista propaló la idea de que el conflicto que vivía el mundo era el contrapunto entre democracia y totalitarismo. El capitalismo salió triunfante de esa confrontación en su modalidad más salvaje, la neoliberal. Sin embargo, el neoliberalismo sustentado en la exclusión, en la polarización social, en la desciudadanización no puede sostener las promesas democráticas que en los años del keynesianismo se hicieron. Esto se debe a que el neoliberalismo impulsó la idea de un sistema político-económico autorreferencial y autolegitimado, que derivaba sus principios de acción de los mecanismos del mercado y de la racionalidad económica, ambos reflejados en la burocracia del estado. Una forma de organización estatal que, en contra de lo promulgan por su defensores, nunca ha sido neutral respecto al régimen democrático, los actores políticos y económicos, y principalmente los valores que intervienen en su funcionamiento (Orjuela, 2007). La élite empresarial en buena parte de los gobiernos nacionales ha ocupado al estado mediante representantes partidistas con el objetivo de extender sus redes de influencia. Para estos políticos-empresarios el modelo de gestión de los gobierno nacionales deben ser similares, sino es que idénticos, a los esquemas de administración capitalista, bajo el supuesto de que la gestión empresarial es más eficiente y superior que las prácticas burocráticas tradicionales de la gestión pública.

Así, la ciudadanía tal como la visualizó Marshall en 1948, es decir como algo que se sustentaba en una equidad básica, resulta impracticable. Las ideas de justicia de teóricos liberales como John Rawls resultan subversivas para los cánones actuales. Y en los países en los cuales aparecen vastos movimientos sociales que se transforman en movimientos electorales, las reglas de la democracia procedimental se convierten en un peligroso y contraproducente espacio. En esos países, estos 
movimientos sociales construidos al calor de la protesta popular tampoco se conforman con la democracia procedimental, visualizan a la democracia como algo que recupera las reglas liberales y representativas pero las profundiza a través de la democracia participativa. La reacción conservadora, aun la derecha ilustrada, califica estos procesos como muestra de un peligroso retorno de un arcaísmo político: el populismo.

El fantasma del populismo ha sustituido al del comunismo en la América latina de los albores del siglo XXI. El calificativo de populismo, en una acepción equívoca y ahistórica, es hoy uno de los principales arietes ideológicos de la reacción conservadora en la región. Para no pocos pensadores el populismo hoy representa un problema para los estados democráticos latinoamericanos, en el entendido de que en su apelación al "pueblo" como gran conglomerado social, se diluyen las identidades particulares de los ciudadanos y los subsume bajo un todo homogéneo. Sin embargo, por el contrario de lo que la perspectiva reaccionaria asume, la idea de "pueblo" presente en los discursos y las plataformas de los gobiernos de izquierda ha cumplido con reunir detrás de un proyecto político a la mayor parte de las franjas sociales que han sufrido las consecuencias del neoliberalismo durante los últimos veinte años. Una forma política que reta la conceptualización de la política como un asunto meramente ejercido entre y por sujetos individuales y que reivindica la noción de un grupo de sujetos nombrado como un "nosotros", "una comunidad en torno a una disputa particular que pone en evidencia la ausencia de la comunidad" (Arditi, 2007:137).

Esta nueva aparición del fantasma "populista" obedece a la crisis del modelo político y económico neoliberal, un momento en el que los espacios de bienestar se han reducido drásticamente generando brotes de movilización popular en busca de cambios en las estructuras de estado. En este sentido, el populismo se debe entender como un espacio por naturaleza de democracia en tanto se encuentra articulado fuertemente a la llamada "interpelación popular democrática" (Laclau, 1977:144). Una forma de movilización a favor de la ampliación del espacio de participación popular en la política oficial debido a que los procesos políticos en muchos de los países latinoamericanos durante largo tiempo han sido de naturaleza cerrada y oscura, terminando por expresar a la llamada política democrática como un conjunto de recetas y formas expresadas en instituciones oficiales que pretenden absorber toda la actividad política y social. Esta situación ha llevado a un auge de democracias de "forma" en demérito del "fondo", aspectos que son criticados y abordados por los movimientos de izquierda calificados como populistas. Movimientos que se encuentran en la búsqueda de mayor injerencia en la política y en un esfuerzo por "democratizar" aquello que ya se ha cerrado (Mény, 2005:63).

Otra de las críticas reaccionarias propagadas actualmente va en el sentido de señalarla como una formación política "exótica" que cumple únicamente con "satisfacer los deseos iconoclastas de la multitud", tomando prestados puntos del populismo clásico como la defensa de los pobres o el orgullo nacional (Hermet, 2001:21). Así, los llamados populismos modernos tendrían características de movimientos "atrapalotodo" que se aprovechan de las frustraciones de obreros, desempleados, campesinos, todos grupos que comparten la "obsesión de ver desaparecer su universo material y cultural bajo el efecto de la mundialización y de un hundimiento concomitante de las soberanías nacionales" (Hermet, 2001:29). En síntesis, un movimiento político que es en esencia acomodaticio a los problemas de las democracias establecidas, y por tanto, demagógico, sus propuestas políticas son lejanas a la realidad. Realidad que ha sido previamente determinada por el dominio de las políticas neoliberales que se adhieren fuertemente a una economía política de lo posible: "una economía y una política más preocupadas por la ética de las consecuencia que por la ética de las convicciones", un medio en el que las políticas económicas deben ser más pragmáticas y "más atentas a la eficacia que a la integridad ideológica" (Santiso, 2001:224). De esta forma para los críticos del populismo las ideas de reforma política y social que se dirijan en una dirección contraria a los cánones del neoliberalismo económico serían abiertamente irresponsables y fuertemente ideológicas: políticas irresponsables y demagógicas. 
Como corolario de esta serie de críticas esta aquella que identifica al populismo como un "riesgo para la democracia" en tanto relativiza o abiertamente desprecia a las instituciones y los procedimientos democráticos en boga. Esto porque para la movilización popular la democracia se presenta como algo que va más allá de las formas meramente procedimentales, situación que interpela directamente a la idea de que la política se sintetiza y realiza en una serie de procedimientos. En consecuencia las prácticas asociadas a la democracia directa como las consultas o los referéndums atentarían contra el espíritu democrático representativo, supuesto puerto de llegada final y realización máxima de la democracia liberal. Las propuestas de redistribución ampliada de la renta y de rehabilitación de las industrias nacionales hablarían de mentes retrogradas y de corruptelas en puerta, propias de un pasado ya rebasado y por sí mismas insostenibles (argumento con claras omisiones a la revisión de las razones fuera de la esfera nacional por la cuales se sucedió su colapso).

Visto desde nuestra perspectiva, en las experiencias recientes los movimientos sociales llamados denostativamente como populistas, poseen en el centro un conjunto de reivindicaciones sociales producto del gran crecimiento de la desigualdad y la exclusión social. El mote de populistas en este sentido parecería obedecer más a una forma de descalificación hacia quiénes elevan reclamos considerados dentro de los marcos constitucionales de los estados nacionales occidentales, una situación que demuestra contradicción en aquellos críticos que se autoproclaman como demócratas y que reniegan a reconocer la legitimidad de las demandas de ciudadanización efectiva y participación política soberana y popular. Planteado de esta manera es posible observar como la idea de democracia se ha convertido en un discurso que cumple con relegar a aquellas formas consideradas como impropias, como expresiones que se encuentran fuera del mundo de la razón y la justicia (De la Torre, 2007:69). Un discurso que ha sido objeto de un manejo maniqueo para excluir y señalar a un otro irracional, una otredad que marca la diferencia entre los verdaderos y los falsos demócratas (Arditi, 2004). Situación que se ve reforzada por la idea de que los populismos en sí mismos son ejemplos de liderazgos demagógicos, donde éste pesa más que cualquier esfuerzo de estructuración y propuesta política legítima, amenazando con romper los diques que el modelo procedimental de la democracia representativa garantizaría. De igual manera se asume que la presencia de los liderazgos populistas implicaría la formación de una densa red corporativa sobre la organización en movimiento destinada a trasladarse a cualquier espacio que pudiera ocupar. Sin embargo, el riesgo de organización corporativa es siempre un supuesto, dado que esta no es una tendencia que se haya presentado en los movimientos sociales que actualmente ocupan la escena latinoamericana. Más bien, el problema de la organización social parece ser uno de los graves problemas que pesa sobre las democracias representativas de inspiración neoliberal, dado que la imperante situación de injusticia y desigualdades sociales, es precisamente lo que ha causado el derrumbe del orden económico, político y social imperante. En este, la integración no se ha presentado entre la sociedad civil y las estructuras de estado, sino entre las empresas económicas transnacionales y los pocos beneficiados por esta estructura y el poder político que ha terminado por volverse un brazo de los intereses del capitalismo transnacional (Klein, 2007). Desconociendo esta situación, aquellos que se declaran abiertamente en contra de los movimientos políticos de convocatoria masiva y popular se inclinan por mantener la colusión existente entre empresarios y políticos profesionales, a favor de mantener el relativo espacio de libertad de acción en el que se benefician las empresas capitalistas en los estados nacionales con débil regulación jurídica. Ante esta situación, el llamado populismo emerge como un riesgo importante para aquellos que resultan beneficiados de la estructura de poder actual aquellos que ven renacer a un monstruo que parecía haber muerto y desaparecido hacia ya hace algún tiempo. El predominio de la estructura y organización del poder político basado en el procedimentalismo ha dado ya suficientes muestras de su erosión y falta de legitimidad. Este aspecto es precisamente el que las Naciones Unidas, a través del Programa para el Desarrollo, han calificado como el mayor problema de la democracia y la organización política en la zona: la falta de una democratización verdadera al privar las condiciones económicas y sociales fundamentales para su desarrollo. 
En este contexto es precisamente desde donde se debe pensar qué significa el renacer de la pretendida amenaza populista, sobre las connotaciones de la satanización y la estigmatización a priori de la construcción de alternativas y luchas políticas-populares en Latinoamérica. Finalmente el eje central en esta discusión está marcado en buena medida por la hegemonía de la democracia liberal procedimental, en tanto es la forma dominante actualmente sobre la vida política oficial en todos los países de Latinoamérica. La paradoja aquí es que los movimientos han excedido los límites que la democracia procedimental les ha marcado, y en los casos en que han podido aprovechar esta vía para tomar el poder de manera legítimamente, han asumido el proyecto de transformarla. De esta forma las críticas que se les han dirigido desde la perspectiva de la democracia procedimental no han hecho más que demostrar las limitantes del propio modelo procedimental: el populismo se ha vuelto el espejo en el que el modelo procedimental se ve reflejado y se niega a mirar, convirtiéndose en la contraparte necesaria de los pendientes que su acción como modelo de organización política y social han provocado ${ }^{3}$. Los movimientos políticopopulares han terminado por tomar los "daños" causados por el neoliberalismo y los ha encauzado a través de un vertedero común, que los vuelve tanto una bandera de movilización detrás de un proyecto político y social que respalda su aspiración a transformar el poder de estado y sus estructuras predominantes. Movimientos que no han desconocido las potencialidades del reconocimiento de derechos políticos pero que sobrepasan los límites de la democracia procedimental al avocarse al empoderamiento social, no sólo para poder elegir a sus gobernantes como lo marca la democracia procedimental, sino en pos de asumir la construcción de una democracia social que implica participar de "las decisiones que afectan la distribución de los beneficios económicos para así poder gozar de una vida más digna” (Arditi, 2007:133).

La derecha reaccionaria no se equivoca en el uso de esa arma. Hoy es la participación autónoma de los de abajo, la participación de estos desde la sociedad civil, la disputa del poder a las élites tradicionales en el interior del Estado, los caminos que nos pueden llevar a un mundo distinto que el que ahora padecemos.

\section{Bibliografía y fuentes documentales}

Arditi, Benjamin (2004), "El populismo como periferia interna de la política democrática" en $e$ l@tina. Revista electrónica de estudios latinoamericanos, Volumen 2, $\mathrm{N}^{\circ}$ 6, Facultad de Ciencias Sociales, Universidad de Buenos Aires, Argentina. Pp. 63-80

Arditi, Benjamin (2007), "Ciudadanía de geometría variable y empoderamiento social: una propuesta" en Ciudadanía y desarrollo humano, Siglo XXI-PNUD, Buenos Aires, pp.123-148.

\section{Babb, Sara (2001). Managing México. Economists from nationalism to neoliberalism.}

Beinstein, Jorge (2009). "Señales de implosión. Hacia la desintegración del sistema global". Servicio Informativo "Alai-amlatina". 3 de marzo, Buenos Aires.

Bello, Walden (2009). La crisis capitalista y la respuesta política de la izquierda. Conferencia dictada el 21 de marzo 2009 en la Conferencia sobre la crisis global organizada por el Partido de la Izquierda de Alemania. Publicada por la revista electrónica Rebelión.

\footnotetext{
${ }^{3}$ Arditi se he referido a este escenario de desgaste del discurso del liberalismo político como "posliberalismo", es decir, al rebase de la ciudadanía y la política efectivas con relación al formato liberal tradicional (Arditi, 2007:128).
} 
Boron, Atilio A. (2009), "De la guerra infinita a la crisis infinita". Ponencia presentada al XI Encuentro Internacional de Economistas sobre Globalización y Problemas del Desarrollo, La Habana Cuba, 2-6 de marzo. http://www.atilioboron.com

Castro, Nils (2010), “QQué es la nueva derecha?, especial para Argenpress.info, 17 de abril, http://www.argenpress.info/2010/04/quien-es-la-nueva-derecha.html.

CEDIB (2008). "La Bolivia del revocatorio". ALAI AMLATINA, 7 de agosto Cochabamba. info@alainet.org; http://alainet.org

De la Torre, Carlos (2007), "Es el populismo la forma constitutiva de la democracia en América Latina" en Vox Populi. Populismo y democracia en América Latina, Julio Aibar Gaete (coord.), Flacso México, México, D.F., Pp. 55-81

Esteva, Gustavo (2009). "La crisis como esperanza". Revista Bajo el volcán No. 14. Editada por el Posgrado de sociología del Instituto de Ciencias Sociales y Humanidades "Alfonso Vélez Pliego" de la Benemérita Universidad Autónoma de Puebla.

Figueroa Ibarra, Carlos (2008). "América Latina, en el umbral del posneoliberalismo". Revista Metapolítica. Volumen 12, No. 59, mayo-junio 2008. México D.F. ISSN-1405-4558. pp. 55-61. Fukuyama, Francis (1989). "The end of the History". The National Interest. Verano.

Fukuyama, Francis (1992). El fin de la historia y el último hombre. Editorial Planeta, Barcelona.

Guillén, Arturo (2009). "En la encrucijada de la crisis global". Servicio informativo Alaiamlatina. 18 de junio, México D.F.

Hermet, Guy (2001), "Del populismo de los antiguos al populismo de los modernos" en Del populismo de los antiguos al populismo de los modernos, Guy Hermet, Soledad Loaeza, Jean Francois Prud'Homme (comps.), El Colegio de México, México, D.F.

Klein, Naomi (2007), "La Doctrina del Shock. El auge del capitalismo del desastre”, Ediciones Paidós Ibérica, España, Barcelona.

Klare, Michael T. (2009). "Un planeta en el alero: ¿podrán contenerse los virulentos brotes epidémicos de la economía?". Publicado en la revista electrónica sinpermiso. 1 de marzo. http://www.sinpermiso.info/textos/index.php?id=2402

Laclau, Ernesto (1977), "Política e ideología en la teoría marxista", Editorial Siglo XXI, México, D. F.

Long, Guillaume (2008). "El mito de la inestabilidad: Estabilidad política y crecimiento económico en Ecuador". Ecuador Debate No. 74, Revista especializada en Ciencias Sociales. Quito, Agosto.

Mény, Yves (2005), "Populismo y democracia en Europa" en Metapolítica, Vol. 9, Núm. 44, noviembre-diciembre de 2005, México.

Meyer, Lorenzo (2009). “La izquierda”. Periódico Reforma. México, 8 de octubre.

Miranda, Guillermo (2007), "Política curricular, crisis de legitimación y hegemonía neoliberal" en Revista de Ciencias Sociales Volumen 1, Núm. 115, sin mes, 2007. Pp. 13-34, Universidad de Costa Rica, Costa Rica.

Orjuela, Luis Javier (2007), La compleja y ambigua repolitización de América Latina en Colombia Internacional, julio-diciembre, número 066, Universidad de los Andes, Bogotá, Colombia, pp.16-35. 
Ramonet, El fin de una era del capitalismo (2008). Publicado en diversos medios.

Reyna, José Luis (2006), “América Latina: Hacia una nueva geometría política” en Estudios Sociológicos, septiembre-diciembre, año/vol. XXIV, número 003, El Colegio de México, Distrito Federal, México, pp.757-771.

Rodríguez, Octavio (2003), "El presente de la derecha y la ultraderecha en el mundo" en Revista Mexicana de Ciencias Políticas y Sociales, enero-abril, año/vol. XLVI, número 187, Universidad Nacional Autónoma de México, Distrito Federal, México, pp. 177-201.

Santiso, Javier (2001), “¿Del buen revolucionario al buen liberal?” en Del populismo de los antiguos al populismo de los modernos, comp. Guy Hermet, Soledad Loaeza, Jean Francois Prud'homme, El Colegio de México, Centro de Estudios Internacionales, México, D. F., Pp. 215-250.

Stiglitz, Joseph E. (2008a). "La crisis de Wall Street es para el mercado lo que la caída del muro de Berlin fue para el comunismo". Entrevista publicada en la revista electrónica Sinpermiso el 21 de septiembre. http://www.sinpermiso.info/textos/index.php?id=2065

Vivas, Esther (2008), "Los supermercados y la crisis alimentaria mundial." Servicio informativo Alai-amlatina. 3 de diciembre. Barcelona 